\title{
EDITORIAL
}

"In memoriam" de Ernest Lluch, ex-ministro de Sanidad

"In memoriam" to the late Ernest Lluch, former Minister of Health

\section{J.J. Viñes}

Presentamos con satisfacción en el presente numero el documento inédito de la Conferencia de Clausura del I Master en Dirección de Servicios de Salud que el profesor Ernest Lluch Martín (1937-2000) pronunció en la Universidad Pública de Navarra, en Octubre de 1993 sobre "Las Tres dificultades de la gestión sanitaria". Este trabajo que mantiene plena vigencia en el desenvolvimiento del Sistema Sanitario español, viene suscrito por una figura del panorama económico, social, y de compromiso político democrático hasta la extenuación; y cuya vida fue segada por la intransigencia y el fanatismo. Todo ello convierte al Prof. Lluch en un referente del pensamiento de la España contemporánea.

El Profesor Ernest Lluch, fue Catedrático de Historia e Instituciones Económicas, en la Universidad de Barcelona en el periodo 1995-2000; disponía de una amplia formación científica y humanística simultáneamente; fue básicamente un hombre de pensamiento, de reflexión y de análisis histórico y prospectivo de la economía y del pensamiento humano; y realizó una incursión sustancial en el campo de las Ciencias de la Salud, asumiendo la responsabilidad como Ministro de Sanidad. Bajo su dirección impulsó la consolidación de un Sistema Sanitario español hacia la meta final del actual Sistema Nacional de Salud, de carácter universal, equitativo y de financiación pública, a través de la Ley General de Sanidad de 1986, la cual no ha sido ni modificada ni contestada por sectores políticos ó sociales desde entonces. De este modo la incursión política del Profesor Ernest Lluch ha constituido un hito capital para la Sanidad Española.

Su larga trayectoria como investigador, historiador y como autor de múltiples trabajos, libros y ensayos en el campo de la economía, han permitido conocer al autor en su especifica área de conocimiento; y sin embargo en lo que constituye su trayectoria como responsable de la Salud Publica y en consecuencia su pensamiento sanitario, no ha trascendido de su 
círculo de colaboradores y de la dura y especializada lectura de la Ley General de Sanidad. Por ello la publicación a título póstumo del documento que presentamos en la Colaboración Especial de este número, representa una reflexión académica por parte de Ernest Lluch en un momento, que como siempre, la Sanidad española se encuentra en cambio constante y en reforma pendiente.

En nombre de ANALES del Sistema Sanitario de Navarra, deseamos expresar nuestro reconocimiento a quienes han permitido que estos pensamientos sanitarios del Profesor Lluch, sean dados a la estampa: por un lado la Profesora de la Universidad Pública de Navarra $D^{\mathrm{a}}$ Isabel De Val depositaria y transcriptora del texto; y por otro a $\mathrm{D}^{\mathrm{a}}$ Montserrat Lamarca, su esposa, y a $\mathrm{D}^{\mathrm{a}}$ Rosa, $\mathrm{D}^{\mathrm{a}}$ Eulalia y $\mathrm{D}^{\mathrm{a}}$ Mireya, hijas del Profesor Ernest Lluch, "In memoriam". 